\title{
Imunopatogênese da psoríase: revisando conceitos
}

\author{
Reviewing concepts in the immunopathogenesis of psoriasis
}

\author{
Emerson de Andrade Lima ${ }^{1}$
}

\author{
Mariana de Andrade Lima ${ }^{2}$
}

\begin{abstract}
Resumo: O conhecimento sobre a fisiopatogenia da psoríase possibilitou o desenvolvimento de ferramentas terapêuticas que visam ao bloqueio do seu gatilho imunológico. Paralelamente, citocinas como o TNF têm sido reconhecidas como integrantes da etiopatogenia da psoríase e comorbidades a ela relacionadas. Estudos genéticos e epidemiológicos contribuíram efetivamente para as conclusões a que se tem chegado atualmente sobre esta complexa patologia.

Palavras-chave: Antígenos CD4; Células Th1; Fator gênico 3 estimulado por Interferon; Fator de necrose tumoral alfa; Interleucina-4; Psoríase

Abstract: Insights into the pathogenesis of psoriasis led to the development of therapeutic tools aimed at blocking its immunological trigger. In parallel, cytokines such as the tumor necrosis factor (TNF) have been recognized as playing a crucial role in the pathogenesis of psoriasis and its associated comorbidities. Genetic and immunological studies have contributed effectively towards establishing the currently held concepts regarding this complex disease.

Keywords: Antigens, CD4; Interferon-stimulated gene factor 3; Interleukin-4; Psoriasis; Th1 cells; Tumor necrosis factor-alpha
\end{abstract}

\section{INTRODUÇÃO}

Há muitos anos, a psoríase é reconhecida pelas alterações histológicas que lhe são características. No entanto, mais recentemente, as pesquisas imunológicas têm permitido uma nova definição da doença, baseada nas funções genômicas e na análise da expressão gênica. Esses dados trouxeram uma compreensão singular dos processos de regulação da inflamação na psoríase. Desta forma, há a certeza de que a gama de quimiocinas que se expressam na pele lesionada é muito maior do que se admitiu no passado. E, ainda, pode-se afirmar, categoricamente, que as quimiocinas, cuja expressão estaria restrita a linfonodos e tecidos linfoides, estão presentes em alta concentração na lesão psoriásica. ${ }^{1}$

Por esses motivos, a psoríase passou a ser considerada uma inflamação crônica, resultante da estimulação persistente de células $\mathrm{T}$ (linfócitos $\mathrm{CD}^{+} \mathrm{e}$ $\mathrm{CD}^{+}$) por imunógenos de origem epidérmica, envolvendo a imunidade inata e a adquirida. ${ }^{2,3}$

\section{FISIOPATOGENIA}

Os modelos atuais de explicação da fisiopatogenia da psoríase, ao compararem a pele doente com a não-lesionada, demonstram diferenças na composição celular e de mediadores inflamatórios. Quanto à composição celular, enquanto na pele normal há muitas células imaturas de Langerhans e dendríticas, poucos linfócitos $\mathrm{CD} 4+$ e raros linfócitos $\mathrm{CD} 8+$, na pele lesionada há abundância de outros tipos celulares, conforme expresso no quadro $1{ }^{1}$

Expostas as populações celulares envolvidas nas lesões psoriásicas, cumpre explicar as relações moleculares expressas por mediadores inflamatórios e coestimulatórios. Em linhas gerais, tanto na instalação da doença quanto nos episódios de exacerbação, células dendríticas maduras, mieloides e plasmocitoides, são ativadas na epiderme e derme, produzindo mensageiros que promovem o desenvolvimento de subclasses de células $\mathrm{T}$ belper e $\mathrm{T}$ citotóxicas (Th1, Tc1). Estas células $\mathrm{T}$ secretam mediadores (IFN- $\gamma$ ),

Recebido em 28.06.2010.

Aprovado pelo Conselho Consultivo e aceito para publicação em 08.02.2011

* Trabalho realizado na Santa Casa de Misericórdia do Recife - Recife (PE), Brasil.

Conflito de interesse: Nenhum / Conflict of interest: None

Suporte financeiro: nenhum / Financial Support: None

Doutor pela Faculdade de Medicina da Universidade de São Paulo (FMUSP); Coordenador do Ambulatório de Pesquisa em Psoríase e Artrite Psoriásica do Hospital das Clínicas da Universidade Federal de Pernambuco; Professor da Pós-graduação em Dermatologia da Santa Casa de Misericórdia do Recife - Recife (PE), Brasil.

Coordenadora do Ambulatório de Pesquisa em Psoríase e Artrite Psoriásica do Hospital das Clínicas da Universidade Federal de Pernambuco (HC-UFPE) Recife (PE), Brasil.

(C)2011 by Anais Brasileiros de Dermatologia 
QUADro 1: População de células envolvidas nas lesões psoriásicas

\begin{tabular}{|c|c|c|c|}
\hline Células & $\begin{array}{l}\text { Pele não- } \\
\text { lesionada }\end{array}$ & Pele lesionada & Expressão na psoríase \\
\hline $\begin{array}{l}\text { Células de } \\
\text { Langerhans } \\
\text { imaturas }\end{array}$ & Poucas & Muitas & Constituem-se em células dendríticas imaturas, residentes na epiderme \\
\hline $\begin{array}{l}\text { Células } \\
\text { dendríticas } \\
\text { mieloides }\end{array}$ & Poucas & Muitas & $\begin{array}{l}\text { Localizam-se na derme; derivam de monócitos sanguíneos ou de } \\
\text { outras células precursoras mieloides, com forte expressão do } \\
\text { complexo maior de histocompatibilidade classe II, responsável por } \\
\text { intensa imunoestimulação de linfócitos T, devido à grande liberação } \\
\text { de IL-12 e IL-23 (citocina com ação inflamatória direta, que promove } \\
\text { o aumento e a ativação de linfócitos das linhagens Th1 e Tc1) }\end{array}$ \\
\hline $\begin{array}{l}\text { Células } \\
\text { dendríticas } \\
\text { maduras }\end{array}$ & Ausentes & Abundantes & $\begin{array}{l}\text { Após maturação pela ação do TNF- } \alpha \text {, essa linhagem, que deriva da } \\
\text { linhagem mieloide, apresenta maior capacidade de ativação de } \\
\text { células T, diferente daquelas presentes em pele normal }\end{array}$ \\
\hline $\begin{array}{l}\text { Células } \\
\text { dendríticas } \\
\text { plasmocitoides }\end{array}$ & Ausentes & Muitas & $\begin{array}{l}\text { Ativadas, sintetizam e liberam grandes concentrações de interferon } \alpha \\
\text { (IFN- } \alpha \text { ), estimulando linfócitos T na lesão }\end{array}$ \\
\hline $\begin{array}{l}\text { Linfócitos T } \\
\text { CD4+ }\end{array}$ & Poucas & Abundantes & $\begin{array}{l}\text { Predominam na derme e expressam antígeno cutâneo linfocitário, } \\
\text { que atua seletivamente nas lesões inflamatórias }\end{array}$ \\
\hline $\begin{array}{l}\text { Linfócitos T } \\
\text { CD8+ }\end{array}$ & Raras & Abundantes & $\begin{array}{l}\text { Localizadas na epiderme, expressando } \alpha \text { e } \beta 7 \text { integrinas, que se } \\
\text { ligam à E-caderina, impedindo a formação de desmossomos entre os } \\
\text { queratinócitos }\end{array}$ \\
\hline $\begin{array}{l}\text { Linfócitos T } \\
\text { natural killer }\end{array}$ & Ausentes & Abundantes & $\begin{array}{l}\text { São recrutados do sangue circulante, por quimiotaxia e sintetizam } \\
\text { grandes quantidades de IFN- } \gamma\end{array}$ \\
\hline Neutrófilos & Ausentes & Frequentes & $\begin{array}{l}\text { São recrutados para a lesão pela ação da IL-8 e, embora presentes, } \\
\text { não são considerados causa primária da psoríase }\end{array}$ \\
\hline Macrófagos & Ausentes & $\begin{array}{l}\text { Abundantes e } \\
\text { ativados }\end{array}$ & São essenciais para a ativação de linfócitos B \\
\hline
\end{tabular}

indutores da produção de HLA-DR nos queratinócitos, reativando o processo, que contribui para as alterações epidérmicas e vasculares observadas na psoríase. ${ }^{2}$

$O$ processo inicial de ativação das células $T$ ocorre via células apresentadoras de antígeno, maturadas por peptídeos antigênicos oferecidos pela HLAI ou HLA-II na superfície destas células, com a participação de moléculas como o fator de ativação de linfócitos (LFA-1 - integrina composta de CD11a e CD18) e molécula de adesão intracelular (ICAM-1), as quais favorecem a manutenção desta adesão. Esta ligação conta com a participação de sinalizadores bioquímicos e coparticipação de outros agentes, particularmente a glicoproteína CD28, localizada na superfície dos linfócitos T, e os CD80 e CD86, situados na superfície das células dendríticas, resultando no aumento de mRNA e transcrição de citocinas como a IL-2, IFN- $\gamma$,
TNF- $\alpha$ e fator estimulador de colônias de macrófagos e granulócitos (GM-CSF), cruciais à ativação do linfócito T. Caso a coestimulação promovida pelo CD28 não ocorra, a ativação dos linfócitos $\mathrm{T}$ é parcial (Figura 1). ${ }^{4}$

Outra interação importante manifesta-se entre as moléculas $\mathrm{B} 7$ e $\mathrm{o}$ antígeno 4 de linfócitos T citotóxicos (CTLA4). A interação B7-CD28 é ativadora, enquanto a ligação B7-CTLA4 emite um sinal de supressão da ativação dos linfócitos T. Colaborando com a ativação, estão algumas proteínas na superfície da célula apresentadora de antígeno, que, quando ligadas ao linfócito T, liberam outros sinais acessórios (Figura 1). ${ }^{1}$

Ainda, a liberação de IL-2 e IL-12 pelas células dendríticas maduras contribuem, respectivamente, para a ativação mitótica e a diferenciação dos linfóci- 
tos T. As células dendríticas maduras, importantes para o processo de ativação linfocitário, atingem essa condição depois da captura do antígeno, mediada por citocinas como GM-CSF, IL- 4 e TNF- $\alpha$. Porém, os estágios tardios de sua diferenciação são regulados pelo contato com os linfócitos $\mathrm{T}^{1,2}$

A comunicação entre CD40 e CD40L autorregula a expressão de CD40 na célula dendrítica. Esta interação também estimula a síntese de $\mathrm{B} 7$ nas células apresentadoras de antígenos e favorece a síntese de altos níveis de IL-2, o que contribui para a ativação e diferenciação dos linfócitos T (Figura 1). ${ }^{1,5}$

$\mathrm{O}$ tumor necrosis factor-related activationinduced (TRANCE), da família do TNF, é sintetizado pelas células $\mathrm{T}$ que, ao se ligarem à célula dendrítica (TRANCE-R), inibem seu processo de apoptose. Diante de todas estas mediações, pode-se considerar que a relação dos linfócitos $\mathrm{T}$ com as células dendríticas é um diálogo contínuo e não um breve monólogo.

Após a ativação das células dendríticas maduras (mieloides e plasmocitoides), inicia-se a cascata inflamatória, com a diferenciação dos linfócitos nas linhagens Th1 e Tc1, por coestimulação, que consiste na interação entre células não-antígeno-específicas. Se esta coestimulação não ocorrer, os linfócitos T sofrem apoptose ou se tornam anérgicos. Todavia, em ocorrendo, desenvolve-se a placa psoriásica. ${ }^{6}$

As células apresentadoras de antígeno, nos linfonodos, desencadeiam a especialização de linfócitos T CD4 e CD8 pelo MHC classe I e MHC classe II, respectivamente, por meio da síntese e liberação da interleucina-12 (IL-12). Esta estimulação promove a transformação dos T CD4+ em Th1 e os T CD8+ em Tc1, células capazes de sintetizar e liberar outras citocinas, dentre as quais estão: interleucina-2 (IL-2),

\section{Sinapse imunológica}

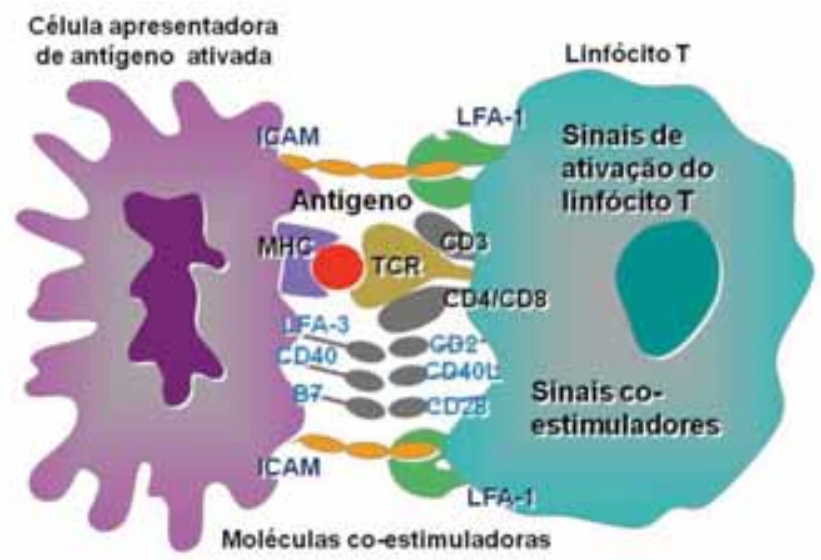

Figura 1: Modelo da sinapse imunológica entre células de Langerhans e dendríticas na pele e linfócito T no início da reação imunológica da psoríase fator de necrose tumoral alfa (TNF- $\alpha$ sigla em inglês), interferon gama (IFN- $\gamma$ ), além de fator estimulador de colônias de granulócitos e leucócitos (GM-GSF) e fator de crescimento epidérmico (EGF) (Figura 2). ${ }^{2}$

Durante seu processo de maturação, as células $\mathrm{T}$ produzem novas proteínas de superfície que habilitam sua passagem dos vasos para a pele. Provavelmente, a mais importante é o antígeno associado ao linfócito cutâneo (CLA), uma molécula de adesão que, auxiliada por citocinas, exerce ação de maturação e quimiotaxia linfocitária, além das moléculas Intracellular Adbesion Molecule-1 (ICAM-1) e Vascular Adhesion Molecule-1 (VCAM-1), as quais contribuem para a criação de um gradiente de avidez, favorecendo a quimiotaxia de linfócitos T e B, assim como de neutrófilos e macrófagos para a lesão, por ativação do endotélio vascular. Atuam também o antígeno funcional linfocitário -1 (LFA-1) e a CD2 no linfócito $\mathrm{T}$, além do antígeno funcional linfocitário - 3 (LAF-3) na célula apresentadora de antígeno ativada. ${ }^{1}$

O TNF- $\alpha$ exerce, dentre outras ações, as de: a) aumento da liberação de citocinas, pelos linfócitos, e quimiocinas, pelos macrófagos; b) aumento da expressão da ICAM-1 dos queratinócitos e da molécula de adesão vascular endotelial 1 (VCAM-1) das células endoteliais, com consequente aprisionamento e maior ativação de linfócitos $\mathrm{T}$, por ficarem expostos por mais tempo a citocinas e quimiocinas circulantes. Além disso, o TNF- $\alpha$ promove aumento da proliferação dos queratinócitos e de células endoteliais com formação de neocapilares e aumento da recirculação linfocitária, favorecendo e mantendo a diapedese linfocitária, que perpetua o processo inflamatório.

Outros fatores importantes para a formação da lesão psoriásica são: a) IFN- $\gamma$ que promove hiperproli-

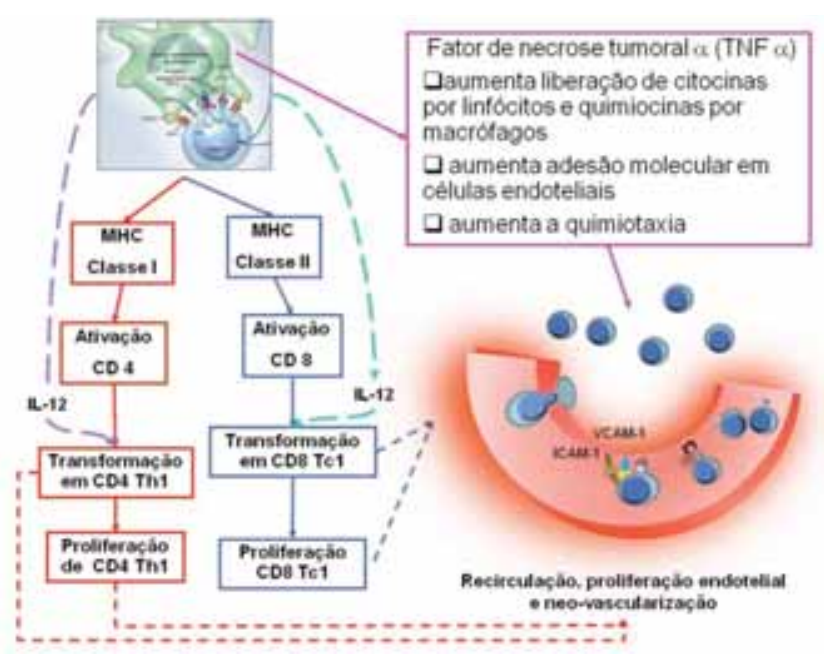

Figura 2: Ação da interleucina 12, promovendo síntese de fator de necrose tumoral

Legenda: MHC - complexo maior de bistocompatibilidade 
feração de queratinócitos por inibição da apoptose, além de aumento da expressão de ICAM-1 nas células endoteliais, facilitando a circulação linfocitária; b) IL17 , que interage com o IFN- $\gamma$ para aumentar a síntese de citocinas pró-inflamatórias pelos queratinócitos, como IL-6 e IL-8, aumentando o influxo de células T na pele, o que contribui para a manutenção da placa

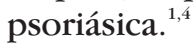

Os queratinócitos, ativados pelas citocinas sintetizadas pelos linfócitos $\mathrm{CD} 4+$ e $\mathrm{CD} 8+$, também liberam citocinas inflamatórias, dentre as quais já foram identificadas: a) TNF- $\alpha$; b) IL-6, que estimula a proliferação de queratinócitos; c) IL-8, que, além de estimular a proliferação de queratinócitos, aumenta a quimiotaxia de neutrófilos que promovem ruptura dos desmossomos de queratinócitos e formação do microabcesso de Munro, além de manter a diferenciação dos linfócitos T para Th1; d) Fator de transformação de crescimento, responsável pela angiogênese e hiperpermeabilidade vascular. ${ }^{7,8}$

A participação de citocinas estimuladoras, como IL-1, IL-6, IFN- $\gamma$ e a presença de células T entre os queratinócitos, provocando injúria da membrana plasmática, são alguns dos mecanismos provocadores da hiperproliferação epidérmica observada na psoríase. Ainda, a liberação de citocinas pelas células T estimula a diferenciação e liberação de IL-8 pelos queratinócitos e consequente recrutamento de neutrófilos, desencadeando mais injúria entre os queratinócitos (Figura 3). ${ }^{4}$

Este processo imunológico associa-se a uma hiperproliferação epidérmica caracterizada pelo aumento em duas vezes do número de mitoses, pela redução do ciclo dos queratinócitos em torno de oito vezes e, consequentemente, uma maturação incom-

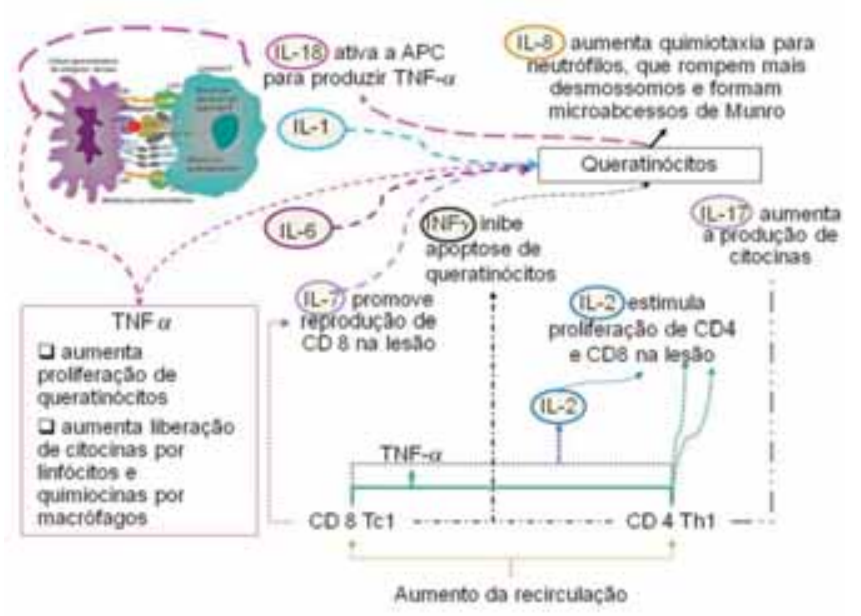

FiguRA 3: Cascata inflamatória da psoríase envolvendo queratinócitos pleta. Isso reduz a síntese de lipídios para formação dos desmossomos pelos queratinócitos. Por outro lado, os linfócitos Tc1 (CD8+) agridem o local das lesões psoriásicas pela liberação de citocinas e conseguem penetrar nos espaços intercelulares dos queratinócitos, facilitando o processo inflamatório.

Dos estudos da fisiopatogenia da psoríase, semelhante ao que havia sido identificado na artrite reumatoide e na doença de Crohn, dada a característica inflamatória imunomediada dessas doenças, ficou evidente que se caracterizava por altas concentrações de TNF- $\alpha$ e de interleucina 1 no local das lesões. Dessa constatação, nasceu a hipótese de que drogas capazes de bloquear a ação do TNF- $\alpha$ poderiam ser úteis no tratamento, embora não se pudesse, à época, avaliar os riscos de tal terapêutica. ${ }^{10}$ Para tanto, era necessário conhecer melhor as funções dessa citocina e das linfotoxinas, às quais também era imputada uma ação importante na pele normal e naquela com psoríase.

Papel do TNF- $\alpha$ e das linfotoxinas nas reações inflamatórias

O TNF- $\alpha$ é uma citocina inflamatória pleiotrópica, produzida por diversas células, como células T e B ativadas, células NK e, na vigência de inflamação, primariamente sintetizada por macrófagos em resposta a vários estímulos pró-inflamatórios. É encontrada em níveis elevados na pele, articulações e plasma de pacientes com psoríase, relacionados à atividade da doença. ${ }^{11}$

O TNF- $\alpha$ é denominado citocina sentinela, porque inicia a defesa em resposta a uma injúria local. ${ }^{12}$ Em baixas concentrações, nos tecidos, exerce efeitos benéficos, como o aumento dos mecanismos de defesa do hospedeiro contra infecções. Em altas concentrações, pode acarretar excesso de inflamação e injúria aos órgãos, como, por exemplo, ocorre na septicemia, quando uma liberação maciça de TNF- $\alpha$ resulta em choque séptico. ${ }^{13}$

Em linhas gerais, o TNF- $\alpha$ aumenta nos processos patogênicos, promovendo a produção de outros mediadores de inflamação e de destruição tecidual, assumindo o papel principal na cascata inflamatória na imunidade inata e na adquirida, mas deve também ser considerado como uma importante citocina próinflamatória participante de uma intrincada rede, mais do que um membro da cascata inflamatória. ${ }^{14}$

A nomenclatura do TNF tem mudado com o tempo. As moléculas anteriormente conhecidas como TNF- $\alpha$ e TNF- $\gamma$, desde o Congresso sobre TNF, em 1998, são denominadas TNF e linfotoxina-alfa (LT $\alpha)$, respectivamente, embora o termo TNF- $\alpha$ ainda seja largamente empregado. Sob a denominação TNF, estão incluídos: o TNF solúvel (sTNF) e o TNF transmembrana (tmTNF), enquanto que, sob a denomina- 
ção LT, são considerados os membros de uma família de linfotoxinas compostas por hélices monoméricas alfa e beta, sendo a L3 a mais importante para o contexto que aqui está sendo abordado. ${ }^{14}$

O mecanismo de ação do TNF consiste em diversas modificações, conforme demonstrado na figura 4. O TNF é liberado das células sintetizadoras (macrófagos, células T, mastócitos, granulócitos, células NK, fibroblastos, neurônios, queratinócitos e células de músculo liso) sob a forma solúvel (formada por três monômeros de $17 \mathrm{kDa}$ ), sendo então convertido em tmTNF, o precursor da forma ligada à membrana celular, sob a ação da enzima de conversão do TNF (TACE). As formas sTNF e tmTNF são biologicamente ativas e sua concentração depende do estímulo tecidual, do tipo e do estado de ativação das células envolvidas na reação de defesa, da concentração de TACE ativa e dos inibidores de TACE, como as metaloproteinases- $3 .{ }^{15}$

A síntese de TNF pelas células pode ser induzida por uma variedade de estímulos. Macrófagos sintetizam TNF na presença de bactérias, vírus, complexos imunológicos e citocinas (como IL-1, IL-7, GM-CSF, IFN- $\gamma$, complemento, células tumorais, irradiação, isquemia, hipóxia e trauma). Estes estímulos desencadeiam a transcrição do mRNA, síntese da proteína próTNF, que é incorporada à membrana celular como tmTNF. Uma vez presente na membrana, o tmTNF induz à síntese de outras citocinas como IL-1, IFN- $\gamma$, IL-2, as quais, por sua vez, realimentam a produção de TNF. No entanto, o TNF pode induzir à síntese de fatores reguladores, como IL-10, prostaglandinas e corticosteroides, que inibem sua transcrição e bloqueiam nova liberação desta citocina (Figura 4). ${ }^{14}$

As duas formas do TNF ligam-se aos receptores de membrana, denominados TNFR e expressos como TNFR1 e TNFR2, que se constituem em glicoproteínas de membrana, que mediam reações distintas. No entanto, há uma especificidade nesta ligação, de tal forma que o STNF liga-se preferencialmente ao TNFR1 e o tmTNF, ao TNFR2, o que desencadeia reações diferentes, a depender do estado metabólico da célula. $\mathrm{O}$ TNFR1 expressa-se em quase todas as células, exceto eritrócitos, enquanto o TNFR2 é mais frequente nas células endoteliais e hematopoiéticas. ${ }^{11}$

O mecanismo primário da ação do TNF (solúvel ou transmembrana), uma vez internalizado ao citoplasma celular pelos receptores de membrana, é a síntese do fator kappa B1 nuclear (NF-кB1), uma família de fatores de transcrição que controla um grande número de genes inflamatórios, promovendo apoptose programada, dependente da ação da caspase-8 e da caspase-3. Esta apoptose, em condições normais, é bloqueada pela enzima de conversão da Fas-associated death domain-like interleucina-1 beta (FADD-IL-
1) (FLICE). No entanto, em uma célula infectada por patógeno, a apoptose não é inibida e o caminho de ativação TNF-TNFR1 é mantido (Figura 4). ${ }^{16}$

No processo inflamatório, também estão envolvidas linfotoxinas (LT), as quais são membros da família TNF, com a qual mantêm grandes semelhanças, embora apresentem diferenças moleculares e biológicas. ${ }^{16}$

$\mathrm{Na}$ figura 5, pode-se observar que o mecanismo de ação das linfotoxinas é bastante semelhante ao do TNF. A linfotoxina alfa-3 (LT $\alpha 3$ ), antigamente denominada TNF- $\alpha$, é estruturalmente semelhante ao sTNF (um trímero de monômeros de $17 \mathrm{kDa}$ ) e se liga aos receptores de membrana TNFR1 e TNFR2, indiscriminadamente, no que difere do sTNF. A segunda linfotoxina é a que contém heterotrímeros alfa e beta, por isso denominada LT $\alpha \beta$ (apresentando duas variantes LT $\alpha 2 \beta 1$ e LT $\alpha 1 \beta 2$, esta em menor concentração). A LT $\alpha \beta$ liga-se aos receptores de membrana LT $\beta R$, embora possa fazê-los aos receptores TNFR1 ou TNFR2, porém, com menor avidez (Figura 5). ${ }^{16}$

A síntese de linfotoxinas pode ser induzida por células $\mathrm{CD} 4+$ esplênicas ou por outras células do baço, desde que estimuladas por IL-4 e IL-7, ou ainda, por ligantes de quimiocinas 19 e 21 (CCL-19 e CCL-21). ${ }^{17}$

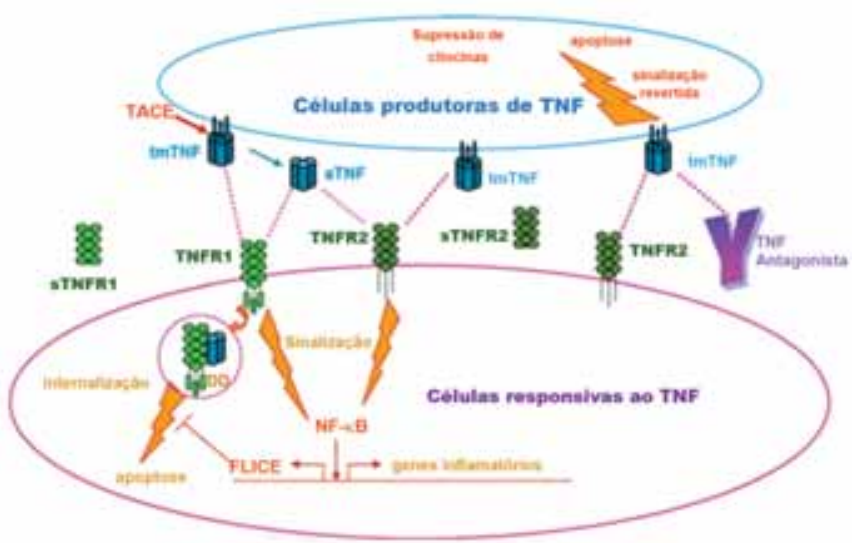

FIgURA 4: Biologia da produção, interação e sinalização do TNF em pele normal

Fonte adaptada: Tracey et al., 2008. ${ }^{14}$

Nota: A estimulação de células produtoras de TNF resulta na expressão de tmTNF na membrana, o qual, por ação da enzima de conversão de TNF (TACE), é quebrado, liberando sTNF Ambos podem ligar-se a TNFR1 e TNFR2, na superfície de células, iniciando os caminhos de sinalização que levam à apoptose e à síntese de $N F-\kappa B$, desencadeando o processo inflamatório. Sob a ação da Fas associada à apoptose com domínio semelhante à IL-1 $\alpha$ (FLICE), os processos inflamatório e apoptótico podem ser inibidos 
Os receptores LTbR estão presentes em fibroblastos estromais, células epiteliais e células mieloides, como monócitos, macrófagos, células dendríticas e mastócitos, mas estão ausentes em linfócitos T, B e natural killers. Sua ligação com LT $\alpha \beta$ depende do contato célula-célula de linfócitos com células estromais circunjacentes. ${ }^{16}$

Deve-se notar na figura 5 que as LT induzem à apoptose e à síntese de NF- $\mathrm{KB}$, mas, diferente da via de interação do TNF, promovem neogênese linfoide, de grande importância clínica pela exacerbação dos processos inflamatórios que promovem.

Mesmo considerando que TNF e LT não são necessárias na imunidade adaptativa, diversos estudos analisaram essa ação, ou seja, na imunidade que envolve a resposta a um antígeno estranho, o qual deve ser processado por células dendríticas, macrófagos, células B ou células apresentadoras de antígeno, para exposição a células T e B, desencadeando respostas imunológicas celular e humoral ao antígeno. ${ }^{18,19}$

Foi determinado que o TNF pode direcionar a diferenciação de monócitos a células dendríticas, ao invés de macrófagos, ou pode induzir à produção de uma série de quimiocinas que facilitam a migração de células dendríticas e o início da resposta imune durante a maturação das células dendríticas. Na resposta das células T aos antígenos, o TNFR2 liga-se funcionalmente ao CD28 e exerce um papel crítico na indução da IL-2 e na sobrevivência dos linfócitos T. ${ }^{20}$

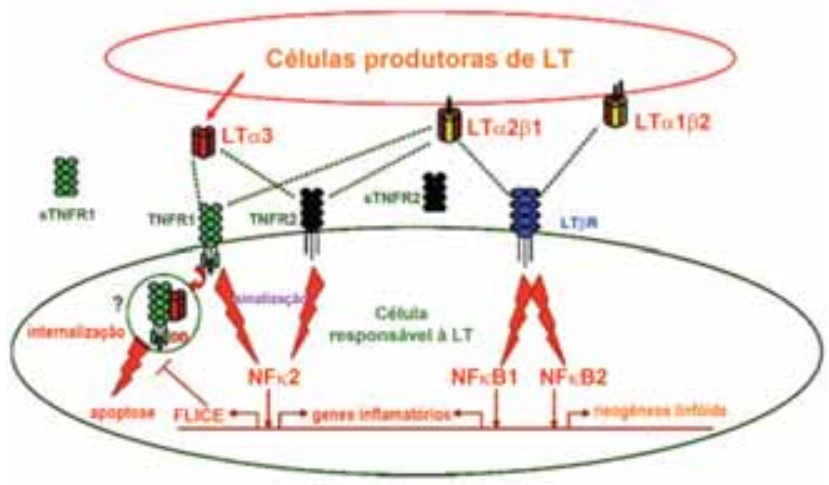

FIGURA 5: Biologia da produção, interação com receptor e sinalização das linfotoxinas em pele normal

Fonte adaptada: Tracey et al., $2008 .^{14}$

Nota: A estimulação de células produtoras de LT resulta na expressão de LT $\alpha 3$ ou da expressão de LT $1 \beta 2$ ou LT $\alpha 2 \beta 1$ Estes ligantes podem unir-se a TNFR1, TNFR2 ou LT $\alpha$ R, iniciando apoptose e síntese de $N F-\kappa B$ e desencadeando o processo inflamatório ou a neogênese linfoide. Sob a ação da FLICE, os processos inflamatório e apoptótico podem ser inibidos
Além disso, o TNF pode estimular a proliferação das células T, mas pode também promover sua apoptose e o término da resposta imune pela morte destas células. Ainda é possível ao TNF aumentar a quimiotaxia de células T para o local da lesão, com a mediação de CXCL-10 pela regulação das moléculas de adesão nas células endoteliais. ${ }^{21}$

Nos processos autoimunes, o TNF pode sequestrar precursores de células $\mathrm{T}$ autorreativas no timo ou mesmo tornar anérgicas células $\mathrm{T}$ circulantes. Este achado sugere que o TNF pode exercer tanto um papel imunossupressor quanto imunoestimulador, dependendo da composição genética do indivíduo, do tempo de doença ou da concentração de TNF circulante. ${ }^{22}$

Na psoríase, o TNF é sintetizado em macrófagos, queratinócitos e células de Langerhans intraepidérmicas e se distribui por toda a epiderme, preferencialmente junto aos vasos sanguíneos da parte superior da derme. Na pele lesionada, o TNFR1 predomina nos queratinócitos, nas células de Langerhans intraepidérmicas e nas paredes dos vasos sanguíneos, enquanto o TNFR2 tem maior expressão nos vasos sanguíneos dérmicos e nas células infiltrantes perivasculares. ${ }^{14}$

Todas essas evidências fizeram com que houvesse o desenvolvimento de uma terapêutica biológica com o objetivo de bloquear a ação do TNF e de seus receptores, reduzindo o processo inflamatório de doenças como a psoríase, a artrite reumatoide e a doença de Crohn. No entanto, a partir da instituição dessas drogas, houve uma recrudescência da tuberculose latente, o que incitou os pesquisadores a analisar também a ação do TNF na tuberculose. ${ }^{23,24}$

O TNFR1, essencial na formação do granuloma do $M$. tuberculosis, liga-se predominantemente na forma solúvel, enquanto o TNFR2 liga-se à forma transmembrana, com papel modesto no combate às infecções bacterianas. O TNF- $\alpha$ regula a expressão da adesão molecular em células endoteliais, estimulando a migração de macrófagos, além de exercer um papel importante na apoptose de células infectadas por essa bactéria. ${ }^{11}$ Este conhecimento torna-se relevante ao analisarmos o maior risco de reativação de tuberculose latente em indivíduos expostos a tratamentos com ação anti-TNF.

\section{Psoríase e comorbidades}

Evidências clínicas permitiram confirmar que a psoríase não é uma doença com manifestação restrita à pele. A associação genética de psoríase a outras enfermidades, como doença de Crohn e diabetes tipo II (CDKAL1), tem também sido relatada mais recentemente, em primeiro lugar, a partir de estudos epidemiológicos que demonstraram alta frequência de 
pacientes psoriásicos com essas doenças e, posteriormente, pela melhor compreensão dos processos imunológicos envolvidos. ${ }^{25,26}$

A semelhança entre os fatores imunológicos responsabilizados no processo de formação da placa de ateroma e aqueles envolvidos na instalação e na progressão de doenças inflamatórias crônicas como psoríase permitiu estabelecer uma relação com a incidência de doenças cardiovasculares. Corroborando estes achados, pacientes portadores de psoríase grave apresentam alta frequência de artrite psoriásica, doença cardiovascular, hipertensão, obesidade, diabetes e risco aumentado para infarto agudo do miocárdio. ${ }^{24,26-36}$

Gisondi et al., estudando um grupo de pacientes com psoríase, identificaram maior prevalência de síndrome metabólica nesses doentes quando comparados ao grupo- controle. Cohen et al. estudaram 340 pacientes com psoríase e 6.643 controles, identificando associação entre a doença e infarto agudo do miocárdio, diabetes, hipertensão, obesidade e dislipidemia, especialmente em homens entre 35 e 50 anos de idade, sugerindo nesses pacientes a presença de síndrome metabólica. Uma avaliação de 16.851 pacientes com psoríase detectou aumento da concentração de colesterol total e de triglicerídeos, associado à diminuição da concentração sérica de HDL, quando comparados com controles. ${ }^{37,38}$
Endossando esses achados, mais de 20 loci gênicos foram detectados interferindo na susceptibilidade à psoríase, relacionados à síndrome metabólica, diabetes tipo II, hiperlipidemia familiar e doença cardiovascular. ${ }^{39-42}$

\section{CONCLUSÃO}

O conhecimento apurado dos mecanismos imunológicos de instalação da psoríase, caracterizando o papel de cada citocina envolvida no desencadeamento da inflamação, possibilitou reconhecê-la como uma doença sistêmica. Essa nova visão estimulou o desenvolvimento de pesquisas, o aprimoramento do diagnóstico, contemplando outras especialidades médicas, e o aparecimento de novas drogas para o controle da doença. Ao agir bloqueando etapas cruciais na progressão da inflamação, estes tratamentos coíbem a progressão da doença e atenuam os sintomas resultantes da sua cronicidade, tornando-se, assim, uma promessa de peso em casos graves e resistentes a terapêuticas convencionais. Cabe ao dermatologista conhecer em profundidade a imunopatogênese da psoríase, o que facilitará a compreensão de novas e atuais descobertas sobre o seu desencadeamento, evolução e controle. 


\section{REFERÊNCIAS}

1. Krueger JG, Bowcock A. Psoriasis pathophysiology: current concepts of pathogenesis. Ann Rheum Dis. 2005;64(Suppl 2):ii30-6.

2. Das RP, Jain AK, Ramesh V. Current concepts in the pathogenesis of psoriasis. Indian J Dermatol. 2009:54:7-12.

3. Krueger JG. The immunologic basis for the treatment of psoriasis with new biologic agents. J Am Acad Dermatol. 2002;46:1-23.

4. Mehlis S, Gordon KB. From laboratory to clinic: rationale for biologic therapy. Dermatol Clin. 2004;22:371-7.

5. Nestle F, Kaplan DH, Barker J. Psoriasis. N Engl J Med. 2009;361:496-509

6. Bolognia JL, Jorizzo JL, Rapini RP, editors. Dermatology. Philadelphia: Saunders Elsevier; 2007. Chapter 9, Psoriasis; p.115-35

7. Galimova ES, Akhmetova VL, Khusnutdinova EK. Molecular genetic basis of susceptibility to psoriasis. Genetika. 2008;44:513-22.

8. Gillitzer R, Ritter U, Spandau U, Goebeler M, Bröcker EB. Differential expression of GRO-alpha and IL-8 mRNA in psoriasis: a model for neutrophil migration and accumulation in vivo. J Invest Dermatol. 1996;107:778-82.

9. Emedicine.com [Internet]. Lui H, Mamelak AJ. Psoriasis, plaque. 2007. [cited 2007 Jul 22]. Available from: http://www.emedicine.com/derm/topic365.htm.

10. Elliott M, Maini R, Feldmann M, Kalden J, Antoni C, Smolen J, et al. Randomised double-blind comparison of chimeric monoclonal antibody to tumour necrosis factor alpha (cA2) versus placebo in rheumatoid arthritis. Lancet. 1994;344:1105-10.

11. Tutuncu $Z$, Kavanaugh A. Rheumatic disease in the elderly: rheumatoid arthritis Clin Geriatr Med. 2005;21:513-25.

12. Feldmann $M$, Steinman $L$. Design of effective immunotherapy for human autoimmunity. Nature. 2005;435:612-9.

13. Goedkoop AY, Kraan MC, Teunissen MB, Picavet DI, de Rie MA, Bos JD, et al. Early effects of tumour necrosis factor alpha blockade on skin and synovial tissue in patients with active psoriasis and psoriatic arthritis. Ann Rheum Dis. 2004;63:769-73.

14. Tracey D, Klareskog L, Sasso EH, Salfeld JG, Tak PP. Tumor necrosis factor antagonist mechanisms of action: a comprehensive review. Pharmacol Therap. 2008;117:244-79.

15. Smookler S, Mohammed FF, Kassiri Z, Duncan GS, Mak Tw, Khokha R. Tissue inhibitor of metalloproteinase 3 regulates TNF-dependent systemic inflammation. J Immunol. 2006:176:721-5.

16. Ware CF. Network communications: lymphotoxins, LIGHT, and TNF. Annu Rev Immunol. 2005;23:787-819.

17. Voon DC, Subrata LS, Karimi M, Ulgiati D, Abraham LJ. TNF and phorbol esters induce lymphotoxin-beta expression through distinct pathways involving Ets and NF-kappaB family members. J Immunol. 2004;172:4332-41.

18. Chomarat P, Dantin C, Bennett L, Banchereau J, Palucka AK. TNF skews monocyte differentiation from macrophages to dendritic cells. J Immunol. 2003:171:2262-9.

19. van Lieshout AW, Barrera P, Smeets RL, Pesman GJ, van Riel PL, van den Berg WB et al. Inhibition of TNFalpha during maturation of dendritic cells results in the deveIopment of semi-mature cells: a potential mechanism for the beneficial effects of TNFalpha blockade in rheumatoid arthritis. Ann Rheum. 2005:64:408-14

20. Kim EY, The HS. Critical role of TNF receptor type-2 (p75) as a costimulator for IL2 induction and $T$ cell survival: a functional link to CD28. J Immunol. 2004:173:4500-9

21. Manes TD, Pober JS, Kluger MS. Endothelial cell-T lymphocyte interactions: iP-10 stimulates rapid transendothelial migration of human effector but not central memory $\mathrm{CD} 4+\mathrm{T}$ cells. Requirements for shear stress and adhesion molecules. Transplantation. 2006;82(1Suppl):S9-14.

22. Valencia X, Stephens G, Goldbach-Mansky R, Wilson M, Shevach EM, Lipsky PE. TNF downmodulates the function of human CD4+CD25hi T-regulatory cells. Blood. 2006;108:253-61.

23. Hernandez C, Cetner AS, Jordan JE, Puangsuvan SN, Robinson JK. Tuberculosis in the age of biologic therapy. J Am Acad Dermatol. 2008;59:363-80.

24. Lima EA, Lima MA, Duarte A, Marques C, Benard G, Lorena V, et al. Investigação de infecção tuberculosa latente em pacientes com psoriase candidatos ao uso de drogas imunobiológicas. An Bras Dermatol. 2011;86:716-24.

25. Gottlieb AB, Chao C, Dann F. Psoriais comorbidities. J Dermatol Treat. 2008:19:5-21.
26. Wolf N, Quaranta M, Prescott NJ, Allen M, Smith R, Burden AD, et al. Psoriasis is associated withpleiotropic susceptibility loci identified in type II diabetes and Chron disease. J Med Genet. 2008;45:114-6.

27. Hansson GK. Inflammation, atherosclerosis, and coronary artery disease. N Engl J Med. 2005:352:1685-95

28. Maradit-Kremers H, Nicola PJ, Crowson CS, Ballman KV, Gabriel SE Cardiovascular death in rheumatoid arthritis: a population-based study. Arthritis Rheum. 2005;53:722-32.

29. Han C, Robinson Jr DW, Hackett MV, Paramore LC, Fraeman KH, Bala MV. Cardiovascular disease and risk factors in patients with rheumatoid arthritis, psoriatic arthritis, and ankylosing spondylitis. J Rheumatol. 2006;33:2167-72.

30. Herron MD, Hinckley M, Hoffman MS, Papenfuss J, Hansen CB, Callis KP, et al. Impact of obesity and smoking on psoriasis presentation and management. Arch Dermatol. 2005:141:1527-34.

31. Neimann AL, Shin DB, Wang X, Margolis DJ, Troxel AB, Gelfand JM. Prevalence of cardiovascular risk factors in patients with psoriasis. J Am Acad Dermatol. 2006;55:829-35

32. Solak Tekin N, Tekin IO, Baruf F, Sipahi EY. Accumulation of oxidized low-density lipoprotein in psoriatic skin and changes of plasma lipid levels in psoriatic patients. Mediators Inflam. 2007;2007:1-5

33. Sterry W, Strober BE, Menter A. On behalf of the International Psoriasis Council. Obesity in psoriasis: the metabolic, clinical and therapeutic implications. Report of an interdisciplinary conference and review. Br J Dermatol. 2007;157:649-55.

34. Shapiro J, Cohen AD, David M, Kodak E, Chodik G, Viner A, et al. The association between psoriasis, diabetes mellitus, and atherosclerosis in Israel: a case-control study. J Am Acad Dermatol. 2006;56:629-34.

35. Sommer DM, Jenisch S, Suchan M, Christophers E, Weinchenthal M. Increased prevalence of the metabolic syndrome in patients with moderate to severe psoriasis. Arch Dermatol Res. 2006;298:321-8.

36. Kurd SK, Richardson S, Gelfand JM. Update on the epidemiology and systemic treatment of psoriasis. Expert Rev Clin Immunol. 2007:3:171-85.

37. Gisondi P, Tessari G, Suchan M, Conti A, Piaserico S, Schianchi S, et al. Increased prevalence of the metabolic syndrome in patients with moderate to severe psoriasis. Arch Dermatol Res. 2006; 298:321-328.

38. Cohen AD, Sherf M, Vidavsky L, Vardy DA, Shapiro J, Meyerovitch J. Association between psoriasis and the metabolic syndrome. Dermatol. 2008;216:152-5.

39. Bastard JP, Maachi M, Lagathu C, Kim MJ, Caron M, Vidal H, et al. Recent advances in the relationship between obesity, inflammation, and insulin resistance. Eur Cytokine Netw. 2006;17:4-12.

40. Bowden DW, Rudock M, Ziegler J, Lehtinen AB, Xu J, Wagenknecht LE, et al. Coincident linkage of type 2 diabetes, metabolic syndrome and measures of cardiovascular disease in a genome scan of the diabetes heart study. Diabetes. 2006:55:1985-94.

41. Gudjonsson JE, Eder JT. Psoriasis: epidemiology. Clin Dermatol. 2007:25:535-46

42. Griffiths CEM, Barker JN. Pathogenesis and clinical features of psoriasis. Lancet. 2007;370:263-71.

\author{
ENDEREÇO PARA CORRESPONDÊNCIA / MAILING ADDRESS: \\ Emerson de Andrade Lima \\ Praça Fleming, 35 Jaqueira \\ CEP 52050.180 - Recife - PE \\ E-mail: emersonderma@terra.com.br
}

Como citar este artigo/How to cite this article: Lima EA, Lima MA. Imunopatogênese da psoríase: revisando conceitos. An Bras Dermatol. 2011;86(6):1151-8. 